\section{A.ATTANASIO ${ }^{+}$, B.BLANK, H.G.SCHEEL ${ }^{+}$, H.DAIGGER ${ }^{+}$, Department of Diagnostic Endocrinology, University Children's Hospital, 7400 Tübingen, FRG}

Onset of sex difference in circulating levels of SHBG in humans with age.

Using a membrane filter method serum concentrations of SHBG were directly measured in 187 healthy children and adolescents as well as in 42 adults. No significant sex difference was observed during infancy and in the first stages of pubertal development. Adult males were found to have signifiçantly lower SHBG leve $f^{s}$ than females of comparable ages $(1.9 \pm 0.9 \mathrm{mg} / 1 \mathrm{vs}$. $4.0 \pm 0.5 \mathrm{mg} / 1 ; p<0.05)$. When the SHBG levels of all subjects were related to age, a significant negative correlation $(r=0.59$, $p<0.001$ ) was found. On the other hand, when only the prepubertal subjects were considered no significant correlation with age was observed. The declining trend in SHBG concentration becomes only evident after puberty stage 2 . This pattern of behaviour has been also seen in another B-globulin, namely TBG. It ist possible that this decline in SHBG level is related to the estrogen/androgen balance recording a sex difference with maturation.

M.B.RANKE, D.GUPTA and J.R.BIERICH

18 Department of Diagnostic Endocrinology, University Children's Hospital, 7400 Tübingen, FRG

Circulating levels of DHA in growth hormone (GH) deficient children with normo-synthesis of cortisol.

Thirty-one children with idiopathic GH-deficiency (7 with IGHD; 26 with MPHD) were subjected to multiple testing of hypothalamopituitary and pituitary-adrenal function. ACTH stimulation and insulin-induced hypoglycemia (I.I.H.) revealed all subjects had normo-synthesis of cortisol ( $\triangle \mathrm{F}$ being greater 10 ug/dl for $\mathrm{ACTH}$, and greater $7 \mathrm{UG} / \mathrm{dl}$ for I.I.H.). LH-RH testing recorded mixed results with 11 of the MPHD-patients showing a decreased level of stimulation. However, when the circulating levels of the major adrenal androgen dehydroepiandrosterone (DHA) were levels compared with age-matched controls ( $p<0.01), 11$ being below normal range. We conclude that although the dynamic tests indicate a normally functioning adrenal corticosteroid secretion in GH-deficient subjects the level of DHA is of pathophysiological interest and may indicate towards a different mechanism with regard to the regulation for this hormone.
E. TOPPER " I. GIL-AD and Z, LARON. Institute of Pediatric and Adolescent Endocrinology, Beilinson Medical Center \& Sackler School of Medicine, Tel Aviv University, Israel.

Oral clonidine, an effective $\mathrm{hGH}$ provocative test.

A single oral dose of clonidine - HCl $\left(0.15 \mathrm{mg} / \mathrm{m}^{2}\right)$ administered to 26 healthy subjects $(17 \mathrm{M}$ and $9 \mathrm{~F})$ aged $6-17$ years induced a marked and consistent increase in plasma hGH from $4.9 \pm 1.3 \mathrm{ng} / \mathrm{ml}(\mathrm{m}+\mathrm{SEM})$ to $34.6+4.5$. These values were higher than those $\bar{r}$ registered during insulin $(0.1 \mathrm{U} / \mathrm{kg}$ i.v. $)$ hypoglycemia in 5 of these children $(12.2 \pm 1.7 \mathrm{ng} / \mathrm{ml})$. No false negative responses were observed. in 7 proven $h \mathrm{GH}$ deficient patients no change of the low basal hGH levels was found. Plasma insulin and cortisol levels decreased in both healthy and hypopituitary children. by $50 \%$ from baseline. No significant change in blood glucose, hPr1, LH, FSH and TSH was found. Blood pressure decreased by $20 \pm 2 \mathrm{~mm} \mathrm{Hg}(\mathrm{m}+\mathrm{SEM})$ in the healthy subjects and $25 \pm 4 \mathrm{~mm} \mathrm{Hg}$ in the hGH deficient patients. Drowsiness was the only noted side effect. Clonidine probably enhances hGH and inhibits insulin secretion via an $\propto$ adrenergic stimulation. It is concluded that administration of oral clonidine is a simple potent and reliable hGH provocative test.

Z. Laron - Established Investigator of the Chief Scientist's Bureau Ministry of Health. examined, the group of GH-deficient patients showed decreased

1 L.DAVID,J.CORNIAU ${ }^{\circ}$, E.ABOUKHALIL ${ }^{\circ}$, B. BETEND $^{\circ}$ and R. FRANCOIS. Service de pédiatrie Sbis, hôpital Edouard Herriot and U.E.R. Alexis Carrel, Lyon, France. Evaluation of a short intravenous metyrapone (SU) test in children.

The su test remains the best available in the assessment of the activity of the pituitary-adrenal axis. However, in the most usual procedures, using oral SU, it is an expensive test due to the 2 to 5 days hospitalization. We have evaluated a protocole using IV.SU in 25 normal infants and children (age $9 \mathrm{~m}$ to $14.5 \mathrm{y}$ ) and 9 patients ( 9 to $18 \mathrm{y}$ ) with pituitary adrenal dysfunction attested by the classical oral su test. SU $(1 \mathrm{~g} / \mathrm{m} 2)$ was infused in $300 \mathrm{ml} / \mathrm{m} 2$ of saline for 2hours (NB : the infusion was painful with smaller saline diluent volume). Plasma cortisol (F), 11 deoxycortisol (S) and ACTH were determined by competitive protein binding assays and radioimmunoassay at $0,2,3$ and $4 \mathrm{~h}$. The main hormonal changes were observed at 3 and $4 \mathrm{~h}: \mathrm{F}(\mu \mathrm{g} / 10 \mathrm{ml})$ decreased from mean \pm SD $15.3 \pm 5.6$ to $3.1 \pm 1.8$; S increased from mostly undetectable values $(<0.1$ in $21 / 25$ to 1.4 ) to $6.4-22 \mu \mathrm{g} /$ $100 \mathrm{ml}$. The changes in plasma ACTH were unconsistant. In the 9 patients $\mathrm{F}$ decreased from $6.9 \pm 4.9$ to $1.2 \pm 1.0 \mu \mathrm{g} / 100 \mathrm{ml}$. Low basal $S$ values ( 0.1 in $8 / 9$ and 1) increased to $1.7-6.8 \mu \mathrm{g} / 100 \mathrm{ml}$; only 1 patient reached a plasma $S$ value overlapping the normal range. There was no remarkable change in plasma ACTH. There was no particular side-effect. In conclusion, a $2 \mathrm{~h}$ IV.SU test using plasma $S$ determinations at 0,3 and $4 \mathrm{~h}$ appears as safe, reliable, and inexpensive for the assesment of the activity of the pituitary-adrenal axis. There seems no advantage in using plasma $F$ or ACTH determinations. H.MOELIER ${ }^{+}$, W.ROSENDAHL ${ }^{+}$, D.GUPTA and J.R.BIERICH Z. DICKerman, I. GIL-AD*, S. TIANo ${ }^{\star}$, R. WIEZMan ${ }^{*}, A$. WIEZMAN ${ }^{*}$ and $Z$. LARON. Institute of Pediatric and
Adolescent Endocrinology, Beilinson Medical Center t. of Adolescent Psychiatry D, Geha Psychatric Hosand the Dept Non-specific growth hormone stimulation by synthetic $\mathrm{LH}-\mathrm{RH}$ in adolescent schizophrenics.

The effect of $\mathrm{LH}-\mathrm{RH}\left(50 \mathrm{mcg} / \mathrm{m}^{2}\right.$, i.v.) on the plasma growth hormone (hGH), prolactin ( $\mathrm{Prl}$ ) and gonadotrophins (Gn) was studied in 10 adolescent schizophrenic boys, aged $158 / 12+4 / 12$ years $(m+S E)$. Their height, weight and pubertal stages were appropriāte to their chronological age. As controls served 9 matched normal boys. Before initiation of antipsychotic treatment in 8 out of the 10 schizophrenics LH-RH induced a marked rise of the plasma hGH from $2.5+0.6(\mathrm{~m}+\mathrm{SE})$ to $15.5+2.4 \mathrm{ng} /$ $\mathrm{ml}(\mathrm{p}<0.001)$ at $45-90$ mins. No effect was observed in the normal controls. The mean plasma Prl levels showed a slight but not significant increase from $8.4+1.4$ to $12.7 \pm 1.5 \mathrm{ng} / \mathrm{ml}$. The $\mathrm{Gn}$ response to $\mathrm{LH}-\mathrm{RH}$ was appropriate for the respective pubertal stage in all patients. Six patients were restudied 3 mos following treatment with the antidopaminergic drugs (chlorpromazine, thioridazine or haloperido1). Their basal Pr1 rose to 27 to $300 \mathrm{ng} / \mathrm{ml}$. Their mean basal plasma hGH level was $2.0+$ $0.6 \mathrm{ng} / \mathrm{m} 1$ and only one boy maintained a positive $\mathrm{hGH}$ response to LH-RH. It is postulated that the abnormal stimulation of hGH by LH-RH in young schizophrenics is caused by an excess brain dopaminergic activity.
22

Department of Diagnostic Endocrinology, University Children's Hospital, 7400 Tübingen, FRG

Abnormal profile of cortisol metabolism in two children with juvenile hypertensive syndrome.

Dynamic testings for pituitary and adrenal activity in 2 bloodrelated children (boy $10.5 \mathrm{yr}$; girl $8.0 \mathrm{yr}$ ) with juvenile hypertensive syndrome associated with low plasma renin activity and other characteristic symptoms of mineralocorticoid excess failed to show any overproduction of aldosterone. For other steroids also the profiles were not grossly deviated except androgen and DOC excretions were slightly elevated. Both subjects were without any virilization and daily $25 \mathrm{mg}$ of cortisol failed to improve clinical condition. Histological study of the male subject's adrenal cortex revealed strangely not hyperplasia but hypoplasia. Daily dexamethasone treatment improved hypertension and hypokalemic alkalosis. Extensive analysis of urinary steroids revealed the existence of $5 \alpha$ and $5 \beta$ epimers (not separated) of dihydrocortisol (boy 107.04 ug; girl 95.76 ug) and dihydrocortisone (boy 87.881 ug; firl. 80.84 ug where the former was present in much larger quantities than that found by Ulick et al. (1977) in a 3-yr-old girl and recently postulated as an effective mineralocorticoid by Marver and Edelman (1978). 